\title{
Supply chain management and performance of brewing firms in South-South, Nigeria
}

\author{
P. I., Ohue ${ }^{1 *}$ and P. A., Akhator ${ }^{2}$ \\ 'Department of Business Administration, Faculty of Management Sciences, Nnamdi Azikiwe University, Awka, \\ Anambra State, Nigeria. \\ ${ }^{2}$ Department of Business Administration, Faculty of Management Sciences, Ambrose Alli University, Ekpoma, \\ Edo State, Nigeria. \\ ${ }^{*}$ Corresponding author. Email: ohuepaulitua@yahoo.com
}

Copyright (c) 2021 Ohue and Akhator. This article remains permanently open access under the terms of the Creative Commons Attribution License 4.0, which permits unrestricted use, distribution, and reproduction in any medium, provided the original work is properly cited.

Received 17th January, 2021; Accepted 8th February, 2021

\begin{abstract}
The broad objective of this paper is to determine the nature of relationship that exists between supply chain management and performance of brewing firms in South-South, Nigeria. Specifically, this study seeks to ascertain the extent of relationship between agile supply chain and organizational innovation. The study was fastened on Ludwig von Bertalanffy systems theory of 1950s. Survey research design was adopted for the study, a total population of two hundred and forty-eight (248) was used for the study. Census sampling method was used for the study because the population is a manageable size. The data collection tool employed by the researcher was the questionnaire, while the analysis of the data was done using the linear regression analysis. Results obtained from the test of hypothesis revealed that a strong significant positive relationship exists between agile supply chain and organizational innovation ( $F=6755.312 ; R$-squared $=0.853 ; \mathrm{P}<.05$ ). Based on the findings, the study concluded that there exists a strong significant positive relationship between supply chain management and performance of brewing firms in South-South, Nigeria. Base on that, the study recommended an enactment and implementation of an agile supply chain strategy by the production department of the focused brewing firms as it could impact organizational innovation.
\end{abstract}

Keywords: Agile supply chain, organizational innovation, organizational performance, supply chain management.

\section{INTRODUCTION}

The dynamic nature of the business environment organizations exist has increased the sum of challenges organizations are faced with. As compared to the traditional business environment, the current firm habitats within which organizations operate is in constant flux (Chen and Lin, 2009). As a result, the success of a business does not only depend on its individual performance, it also depends on the distinct roles of other related entities in an organization's supply chain. Increasing competition has made supply chain management an important issue for production managers of manufacturing firms (Kumar et al., 2006). The flexibility of the supply chain management strategy adopted by a typical manufacturing firm is key. Flexibility could be the capacity to adjust to changes in output mix, production volume, or design as well as reaction to changes in an organization's work environment. In general, flexibility is defined as the aptitude of an entity to efficiently and effectively adapt to foreseen and unforeseen changes in its firm habitats (Tummala et al., 2006). A particular organization cannot determine the efficiencies of a supply chain. Therefore, management of the supply chain through an adoption of the required strategy could be essential (Clos et al., 2003).

Supply chain management could in one way or the other affect the performance level of a manufacturing firm. However, several Nigerian manufacturing firms has done little in this regard. This has led to the development of an ineffective and inefficient supply chain by these manufacturing firms. There is the existence of a non-agile 
supply chain in these firms. The existence of a non-agile supply chain in these firms could retard the innovative ability of these manufacturing firms, the ability of these firms to make the right quantity and quality of products available to customers at the right time.

Recent studies have considered the effect of supply chain management on performance of manufacturing firms in Nigeria and other climes (Mohamed et al., 2012; Hamid and Hamid, 2014). However, there is inadequate study on the subject in Nigerian brewing firms. This gives credence to the determination of the effect supply chain management has on the performance of brewing firms in South-South, Nigeria.

An observation of the studied brewing firms by the researcher revealed that the adopted supply chain strategy was not responsive enough to the needs of the key stakeholders in the supply chain. In other words, the chosen supply chain strategy lacked agility. This by implication could retard the innovative prowess of the studied brewing firms. The study of Popoola (2019) suggests that a non-responsive supply chain could negatively impact the innovative abilities of a firm.

Therefore, the broad objective of this study is to examine the relationship between supply chain management and performance of brewing firms in South-South, Nigeria. Specifically, this study seeks to ascertain the nature of relationship existing between agile supply chain and organizational innovation.

\section{REVIEW OF RELATED LITERATURE}

\section{Conceptual review}

\section{Supply chain management (SCM)}

Supply chain regulation (SCM) is a system of managerial practices which includes sourcing raw materials, manufacturing and assembling products, conducting warehousing and inventory, monitoring supply and demand, distributing and delivery of finished goods to the customer (Windischer and Grote, 2003; Agus, 2010). Various ideas have been used to explain the concept SCM. Schonsleben (2004) defines SCM as coordination of strategic and long-term relations in logistics networks (Windischer and Grote, 2003). According to Quinn (1997), supply chain management includes all of those activities associated with moving goods from the raw-material stage to the final stage of consumption. This includes sourcing and procurement, output scheduling, order processing, inventory management, transportation, ware-housing and client service. SCM also embodies the information systems which are necessary to monitor all of those activities. Base on the meaning of supply chain management given by various scholars, the researchers see supply chain management as all activities geared towards tracking merchandise from the sourcing of raw materials to the feedback information from end users. Popoola (2019) contends that some strategies of supply chain management are information sharing, agile supply chain, optimization and trust enhancement. This study is focused on agile supply chain. Agile supply chain was used for this study because previous studies by management scholars reveals that an agile supply chain could impact a firm's ability to meet the ever changing needs and wants of consumers/customers (Schonsleben, 2004).

\section{Agile supply chain}

The opinion of agile supply chain has been introduced for enactment and implementation of the reliable strategies for the sustenance of the supply chain (Harrison et al., 1999 as cited in Khalil et al., 2019). Agility in terms of supply chain management focuses on "responsiveness" (Lee and Lau, 1999 as cited in Maalouf, 2018; Christopher and Towill, 2000). Agility is cooperation to enhance competitive advantage in the organization. Agility entails buyer responsiveness, individuals and information, cooperation inside and between firms and suitable for an organization's change initiative when necessary. In other to be actually agile, a supply chain must possess certain qualities which include: market-sensitivity, virtuality, process-integration and networking (Kisperska-Moron and Swiercze, 2009). From the foregoing, an agile supply chain can be viewed as one that is very responsive to the demands of the key stakeholders in an organization's supply chain. The utilization of an agile supply chain by a typical manufacturing firm could impact the long term goals and objectives of the firm.

\section{Organizational performance}

Selecting performance measures is intended to make sure organizations accomplish the specific (collaborative) aim that they set. The supply chain performance measures that a business entity sets for itself and others should be specific, measurable and evaluated at vertical intervals, and whatever measures are selected should be enforced (Tummala et al., 2006). Typical manufacturing firms have realized the essence of financial and non-financial performance indicators (Fantazy et al., 2010). Organizational performance (OP) is referred to a state of how well enterprises obtain their desired goals. There are various studies available in the past on OP but still, there is no universal definition that can be used to explain OP. Some scholars and researchers use financial performance indicators like profit, shareholder return, return on asset to gauge performance level while others use non-financial indicators like competitive position, organizational innovation, business agility and so on to gauge organizational performance (Yamin et al., 1999 as cited in Khalil et al., 
2019). In this study, we are using a non-financial (organizational innovation) performance indicator. Organizational innovation was used for this study because a firm's innovative ability could serve as a means for meeting customers' expectation.

\section{Organizational innovation}

The concept innovation plays a significant role in enhancing the status of an organization (Mone et al., 1998 as cited in Khalil et al., 2019). It refers to organizational efforts that gives an organization an edge over others on the long-run (Maalouf, 2018). The researchers see organizational innovation as organizational attempt geared towards continuous improvement. One of the prior studies reveals that organizations maintain their strong stance in its industry due to permanent investment in organizational innovation and it must be executed in the entire organization as well as in technology (Pisano, 2015). Despite this, innovation is treated with levity in most manufacturing firms. This because most manufacturing firms do not know the exact policies for effective enactment and implementation of innovative processes (Maalouf, 2018). Also, majority of these firms do not know that the innovative ability of a firm could impact the over-all performance level of the firm in no small measure.

\section{Theoretical framework}

This study is fastened on Ludwig von Bertalanffy systems theory of 1950s. Bertalanffy challenged classical modeling, which were based on static mathematical probability of the systems, and argued that open systems (organizations) are affected by the time factor. Therefore, a dynamic method is required for understanding these open systems. In other words, a fraternization of the key stakeholders and elements in an open system would ensure cohesion and co-operation of these variables/elements in the open system (Lowaon, 2003). This thought is relevant to this study because as an open system, an understanding of all participants in an organization's supply chain by managers and employees of the production department could ensure the adoption of an agile supply chain strategy. This strategy could by extension impact organizational innovation.

\section{Empirical review}

Shobayo (2017) examined the imprint of supply chain management on performance of Nigerian manufacturing firms with specific interest on supply chain strategy and supply chain flexibility. The study adopted an ex post-facto research design using secondary sources to generate the data. The data were gathered from the annual reports of studied manufacturing firms between 2011 and 2016 . Findings revealed that supply chain management does not have a significant overall stamping on performance.

Popoola (2019) examined the supply chain management factors that could enhance the organization performance in manufacturing companies. The population of this study comprise the employees in manufacturing firms in Nigeria. Basically, 400 questionnaires were distributed to the respondents in order to get the required sample size. Structural equation modelling or SEM was used to analyze the inter-relationship among the latent constructs. Findings revealed a positive relationship between the studied variables.

Ugoani and Ugoani (2017) examined supply chain management and productivity in Nigeria. Exploratory research design was used, secondary source of data was used, regression analysis was used to analyse the collected data. Through regression analysis it was found that for a 1 percent increase in supply chain management productivity increases by 1.88 percent.

Sukati et al. (2019) examined the relationship between supply chain management (SCM) and performance of consumer goods industry in Malaysia. The information mixture medium used was a questionnaire which was administrated to a total of 200 managers. The returned copies of the questionnaire were $70 \%$ while $60 \%$ was usable questionnaires. Sample selection was based on convenience sampling. Multiple regression analysis was used to analyze the collected data. The results indicated that supply chain management is related to performance.

Khalil et al. (2019) investigated the association between supply chain management and organizational performance with the mediating role of innovation. Data were collected from 207 small and medium enterprises (SMEs) in Punjab, Pakistan through the questionnaire. Survey research design was used for the study. PLS-SEM was used to analyze the proposed hypotheses. Findings reveal that information sharing, agile supply chain and lean practices had significant effect on organizational performance.

None of the empirically reviewed examined supply chain management as it relates to performance of brewing firms in South-South, Nigeria. This is the lacuna in knowledge that this study seeks to fill.

\section{METHODOLOGY}

\section{Research design}

Survey research design was used for the study. It was used because it aids the confidentiality of data gathered from respondents and the non-manipulation of the sample elements. Survey research design is a type of research design that enables a research observe the actual state of things in the field.

\section{Population of study}

Employees of the production department of the focused 
firms were used for this study. They were used because of the nature of the study. They are Guinness Nigeria Plc, Benin plant (177) and Pabhod brewery Port-Harcourt (71). This gives a total population of (248).

\section{Sample size and sampling technique}

Census sampling was used because the study population (248) was deemed manageable by the researchers. Census sampling is a sampling technique used when a researcher wants to make use of the entire population for a particular study.

\section{Instrument of data collection}

Questionnaire was used for this study. A five point likert scale questionnaire was used for the study. Strongly Agreed (SD), Agreed (A), Undecided (U), Strongly Disagreed (SD) and Disagreed (D).

\section{Validity of the instrument}

Content and face validity test was used by the researchers. This was ensured by adequately capturing the studied variables in the data collection tool. In other words, all the sub-elements of each variable were reflected in the data collection instrument.

\section{Reliability of the instrument}

Cronbach alpha reliability test was used for the study. Suwannoppharat and Kaewsa (2015) assertion of a reliability coefficient of 0.696 and above as an acceptable value was used for the study. The Cronbach's Alpha reliability statistics for supply chain management for 5 number of items show a reliability coefficient 0.813 . Since the reliability value of 0.813 is greater than 0.696 , it shows that the instrument for supply chain management is reliable.

Also, the Cronbach's Alpha reliability statistics for performance for 5 number of items show a reliability coefficient 0.711 . Since the reliability value of 0.711 is greater than 0.696, it shows that the instrument for performance is reliable.

\section{Data analysis}

Regression analysis was used to analyze the data. This was aided by SPSS version 20 (descriptive statistics) and E-views 10 (inferential statistics). The level of significance was $5 \%$ while a $95 \%$ confidence interval reliability was adopted.

\section{RESULTS}

The Table 1 reveals that out of the 248 copies of the questionnaire administered, $185(74.60 \%)$ valid copies were returned. Base on that 185 copies of the questionnaire were used for the analysis of data.

This shows that majority of the respondents returned their copies of the questionnaire.

\section{Research question}

What type of relationship exist between agile supply chain and organizational innovation of brewing firms in SouthSouth, Nigeria? The mean scores of the responses from questions relating to agile supply chain are greater than 2.5 (Table 2). This makes the responses acceptable because a benchmark of 2.5 was used for the study.

The mean scores of the responses from questions relating to organizational innovation are greater than 2.5 (Table 3). This makes the responses acceptable because a benchmark of 2.5 was used for the study.

\section{Test of hypothesis}

Ho: The relationship between agile supply chain and organizational innovation of brewing firms in South-South, Nigeria is not significant and positive. The results (Table 4) obtained revealed that agile supply chain has significant effect on organizational innovation $(\beta=0.830$, $t$-statistics $=$ $15.453, P<0.05)$. Also, agile supply chain is a predictor of organizational innovation (F-statistic $=6755.312$; Rsquared $=0.853 ; P<0.05)$. The predictor variable single handedly explained $85.3 \%$ of the variance in organizational innovation, while the remaining $14.7 \%$ could be due to the effect of the extraneous variables. The durbin-watson value of 2.1 shows that there is no first order serial correlation. This makes the result acceptable.

\section{DISCUSSION}

Findings obtained from the test of the formulated hypothesis revealed that the relationship between agile supply chain and organizational innovation of brewing firms in South-South, Nigeria is significant and positive. This corroborates the work Popoola (2019) who examined the supply chain management and performance of manufacturing companies. Findings revealed a positive relationship between agile supply chain and organizational innovation. The study of Sukati et al. (2019) who examined the relationship between supply chain management (SCM) and performance of consumer goods industry in Malaysia also aligns with findings of the study. The results indicated that an agile supply chain impacts firm innovation. The work of Khalil et al. (2019) who investigated the 
Table 1. Returned and unreturned questionnaire.

\begin{tabular}{lcc}
\hline Parameters & Number & Percentage \\
\hline Returned (Valid) & 185 & $74.60 \%$ \\
Returned (Mutilated) & 11 & $04.44 \%$ \\
Unreturned & 52 & $20.96 \%$ \\
Total questionnaires administered & 248 & $100 \%$ \\
\hline
\end{tabular}

Source: Field Survey, 2020.

Table 2. Descriptive statistics for agile supply chain

\begin{tabular}{lccccc}
\hline Questions & N & Minimum & Maximum & Mean & Std. Deviation \\
\hline Q1 & 185 & 1.00 & 5.00 & 3.6522 & 1.25037 \\
Q2 & 185 & 1.00 & 5.00 & 3.6043 & 1.06175 \\
Q3 & 185 & 1.00 & 5.00 & 3.2036 & 1.27285 \\
Q4 & 185 & 1.00 & 5.00 & 3.5463 & 1.28731 \\
Q5 & 185 & 3.00 & 5.00 & 3.0034 & 0.66568 \\
Valid N (listwise) & 185 & & & &
\end{tabular}

Table 3. Descriptive statistics for organizational innovation.

\begin{tabular}{lccccc}
\hline Questions & N & Minimum & Maximum & Mean & Std. Deviation \\
\hline Q1 & 185 & 1.00 & 5.00 & 3.7442 & 1.21075 \\
Q2 & 185 & 1.00 & 5.00 & 3.7115 & 1.03456 \\
Q3 & 185 & 1.00 & 5.00 & 3.2242 & 1.15271 \\
Q4 & 185 & 1.00 & 5.00 & 3.4827 & 1.24862 \\
Q5 & 185 & 1.00 & 5.00 & 3.7478 & 0.71537 \\
Valid N (listwise) & 185 & & & & \\
\hline
\end{tabular}

Table 4. Regression output.

\begin{tabular}{|c|c|c|c|c|}
\hline \multicolumn{5}{|c|}{ Dependent Variable: ORG_INTN } \\
\hline \multicolumn{5}{|c|}{ Method: Least Squares } \\
\hline \multicolumn{5}{|c|}{ Date: 02/02/21 Time: 10:32 } \\
\hline \multicolumn{5}{|c|}{ Sample: 1185} \\
\hline \multicolumn{5}{|c|}{ Included observations: 185} \\
\hline Variable & Coefficient & Std. Error & t-Statistic & Prob. \\
\hline $\mathrm{C}$ & 2.700000 & 0.164078 & 15.45322 & 0.0000 \\
\hline AGL_SC & 0.830000 & 0.010456 & 84.02030 & 0.0000 \\
\hline R-squared & 0.853414 & \multicolumn{2}{|c|}{ Mean dependent var } & 16.00000 \\
\hline Adjusted R-squared & 0.852420 & \multicolumn{2}{|c|}{ S.D. dependent var } & 5.631239 \\
\hline S.E. of regression & 1.014434 & \multicolumn{2}{|c|}{ Akaike info criterion } & 2.778201 \\
\hline Sum squared resid & 168.6000 & \multicolumn{2}{|c|}{ Schwarz criterion } & 2.723116 \\
\hline Log likelihood & -253.2354 & \multicolumn{2}{|c|}{ Hannan-Quinn criter. } & 2.782311 \\
\hline F-statistic & 6755.312 & \multirow{2}{*}{\multicolumn{2}{|c|}{ Durbin-Watson stat }} & 2.117176 \\
\hline Prob(F-statistic) & 0.000000 & & & \\
\hline
\end{tabular}

association between supply chain management and organizational performance with the mediating role of innovation in small and medium enterprises (SMEs) in Punjab, Pakistan also aligns with findings of the study.
Findings reveal that agile supply chain has significant effect on organizational innovation. Findings of the study and that of Popoola (2019), Sukati et al. (2019) and Khalil et al. (2019) are similar because the response these 
previous researchers got from their field survey is similar to that obtained from respondents by the researchers.

The implication of the findings of this study to management scholars and practitioners is that the findings of this study would create an awareness on the effect an agile supply chain could have on the innovative ability of a manufacturing firm.

\section{Conclusion and Recommendations}

The F-statistic value of 6755.312 , R-squared value of 0.853 confirms the fact that the relationship between agile supply chain and organizational innovation of brewing firms in South-South, Nigeria is significant and positive. Therefore, it could be concluded that the relationship between supply chain management and performance of brewing firms in South-South, Nigeria is significant and positive. The study shows that the nature of the chosen supply chain by the studied firms could impact their innovative abilities. Hence, it is recommended that enactment and implementation of an agile supply chain strategy by the production department of the focused brewing firms should be adopted as it could impact organizational innovation.

\section{CONFLICT OF INTEREST}

The authors declare that they have no conflicts of interest.

\section{REFERENCES}

Agus, A. (2010). Supply chain management, process performance and business performance. Conference of the International Journal of Arts and Sciences, Rome, Italy. Pp. 2225.

Chen, H. J., \& Lin, T. C. (2009). Exploring source of the variety in organizational innovation adoption issues: An empirical study of managers' label on knowledge management project issues in Taiwan. Expert Systems with Applications, 36(2), 1380-1390.

Christopher, M., \& Towill, D. R. (2000). Supply chain migration from lean and functional to agile and customized. International Journal of Management, 5(4), 206-213.

Clos, P., Vokurka, R. \& Lummus, P. (2003). Supply chain management: An empirical review. Journal of Management Information System, 6(7), 12-19.

Fantazy, K. A., Kumar, V., \& Kumar, U. (2010) Supply management practices and performance in the Canadian hospitality industry. International Journal of Hospitality Management, 29(4), 685-693.

Hamid, K., \& Hamid, R. A. (2014). Study of performance measurement practices in supply chain management. Proceedings of the 2014 International Conference on Industrial Engineering and Operations Management Bali, Indonesia, 7th - 9th January, 2014. Pp. 273-285.

Harrison, A., Christopher, M., \& van Hoek, R. (1999). Creating the agile supply chain. Working paper, School of Management, Cranfield University.
Khalil, M. K., Khalil, R., \& Khan, S. N. (2019). A study on the effect of supply chain management practices on organizational performance with the mediating role of innovation in SME's. Journal of Uncertain Supply Chain Management, 7(1), 1-13.

Kisperska-Moron, D., \& Swierczek, A. (2009). The agile capabilities of Polish companies in the supply chain: An empirical study. International Journal of Production Economics, 118(1), 217-224.

Kumar, V., Fantazy, K., Kumar, U., \& Boyle, T. (2006). Implementation and management framework for supply chain flexibility. Journal of Enterprise Information Management, 19(3), 303-319.

Lowaon, J. (2003). A frame work for understanding business organizations. Journal of Business and Management, 7(5), 1926.

Lee, W. B., \& Lau, H. C. W. (1999). Factory on demand: the shaping of an agile production network. International Journal of Agile Management Systems, 1(2), 83-87.

Maalouf, G. (2018). Impact of improved supply chain management on innovation. Arabian Journal of Business Management Review, 8(337), 8 pages.

Mohamed, M. D., Abdellatif, B., \& Fakher, J. (2012). Supply chain flexibility and balanced scorecard: Conceptual model and empirical study in Tunisian companies launched upgrading program. Polish Journal of Management Studies, 5, 34-59.

Mone, M. A., McKinley, W., \& Barker, V. L. (1998). Organizational decline and innovation: A contingency framework. Academy of Management Review, 23(1), 115-132.

Pisano, G. P. (2015). You need an innovation strategy. Harvard Business Review, 93(6), 44-54.

Popoola, M. O. (2019). Supply chain management practices in Nigeria: Developing a framework for enhancement of SCM for organizational performance. Journal of Management and Operation Research, 1(5), 1-16.

Quinn, F. J. (1997). What's the buzz? Logistics Management, 36(2), 43-47.

Schonsleben, P. (2004). Integrated logistics management: Planning and control of comprehensive supply chains. Boca Raton, FL.: St, Lucie Press.

Shobayo, P. B. (2017). Supply chain management and operational performance in Nigeria: A panel regression model approach. International Journal of Entrepreneurial Knowledge, 2(5), 66-77.

Sukati, I., Hamid, A. B., Baharun, R., Tat, H. H. \& Said, F. (2019). A study of supply chain management practices: An empirical investigation on consumer goods industry in Malaysia. International Journal of Business and Social Science, 2(17), 166-177.

Tummala, R., Philips, C., \& Johnson, M. (2006). Assessing supply chain management success factors: A case study. International Journal of Management, 11(2), 179-192.

Ugoani, J. N., \& Ugoani, A. (2017). Supply chain management and productivity in Nigeria. International Journal of Engineering and Manufacturing Science, 7(1), 97-108.

Windischer, A., \& Grote, G. (2003). Success factors for collaborative planning. In: Seuring, S., Miller, M., Goldbach, M., \& Schneidewind, U. (eds), Strategy and Organizations in Supply Chain, Physica, Heidelberg. Pp. 131-46.

Yamin, S., Gunasekaran, A., \& Mavondo, F. T. (1999). Relationship between generic strategies, competitive advantage and organizational performance: An empirical analysis. Technovation, 19(8), 507-518. 